\title{
HVEM Study of the Spinel-Type Phase in Kaolinite-Mullite Thermal Reactions
}

\author{
S. Lee, ${ }^{*}$ Y. J. Kim, ${ }^{* *}$ Y-M Kim, ${ }^{* *}$ W-S Seo ${ }^{*}$ and H-T Jou ${ }^{* * *}$ \\ *Reliability Assessment \& Materials Evaluation Center, Korea Institute of Ceramic Engineering \& \\ Technology, Seoul 153-801, Korea \\ ** Division of Nano-Material \& Environmental Sciences, Korea Basic Science Institute, Daejeon \\ 305-333, Korea \\ ${ }^{* * *}$ Geoenvironment and Resources Laboratory, Korea Ocean Research and Development Institute, \\ Ansan 425-170, Korea
}

The kaolinite-mullite reaction series by heating has been controversial since the new proposal of the reaction mechanism. ${ }^{1}$ The crystal structure and chemistry of an intermediate phase, which is known to be a spinel-type phase, between metakaolinite and mullite is one of the outstanding issues. We have revealed the spinel-type phase coexisted topotactically with metakaolinite using energy-filtered electron diffraction data obtained from the specimen furnace-heated at $920^{\circ} \mathrm{C} .^{2}$

HVEM imaging of the spinel-type phase in the $920^{\circ} \mathrm{C}$-heated kaolinite represents amorphous character while the FFT result shows pseudohexagonal array of spots indicating the existence of a spinel-type phase (Fig. 1). Randomly-oriented mullite crystals are induced by electron-beam irradiation on the $900{ }^{\circ} \mathrm{C}$-heated without forming the spinel-type phase (Fig. 2(a), (b)), while the spinel-type phase which is produced in advance of the mullite coexists with the mullite phase in the $940^{\circ} \mathrm{C}$-heated kaolinite (Fig. 2(c), (d)).

It is suggested that low phase stability of metakaolinite phase against electron beam could not maintain the crystalline structure. As a result, the spinel-type phase was not formed due to the collapse of metakaolinite structure by knock-on effect of the electron beam. Crystallization study ${ }^{3}$ of the amorphous phase in a metallic glass by electron-beam irradiation also supports this idea.

\section{References}

[1] G.W. Brindley and M. Nakahira, J. Am. Ceram. Soc., 42 (1959) 311.

[2] S. Lee, et al., J. Am. Ceram. Soc., 82 (1999) 2841.

[3] T. Nagase and Y. Umakoshi, Sci. Technol. Adv. Mater., 5 (2004) 57.

[4] This work was supported by the Basic Research Program of the Korea Science and Engineering Foundation under Grant No. R03-2002-000-20031-0. 

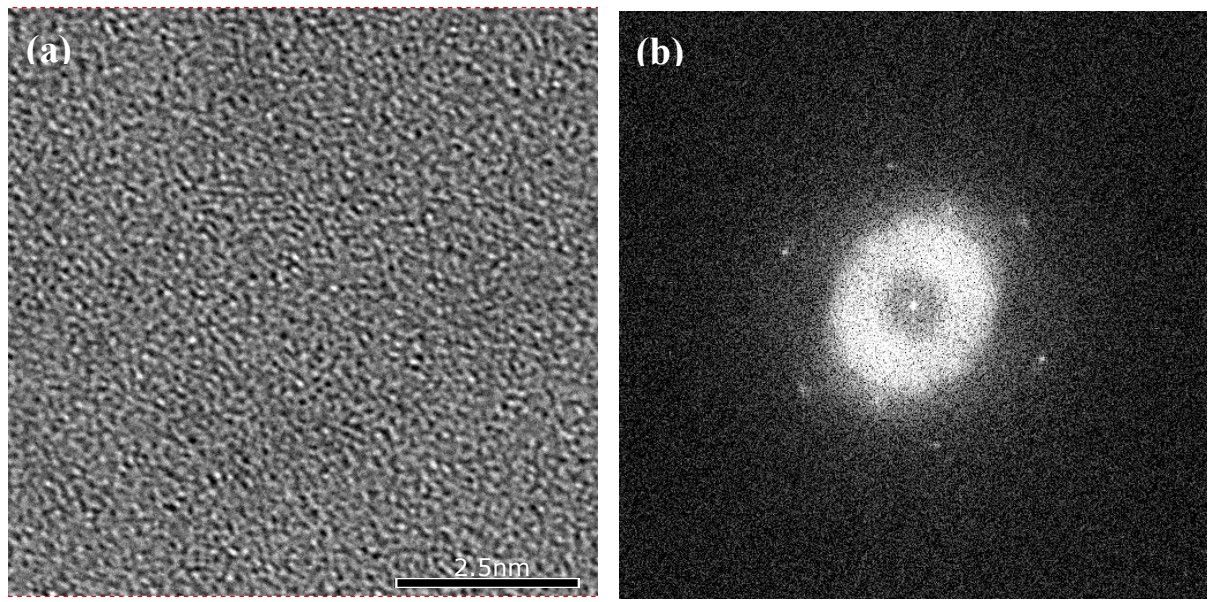

Fig. 1. (a) HVEM image of the spinel-type phase of the $920^{\circ} \mathrm{C}$-heated kaolinite after $40 \mathrm{~min}$ electronbeam irradiation and (b) the FFT result of (a).
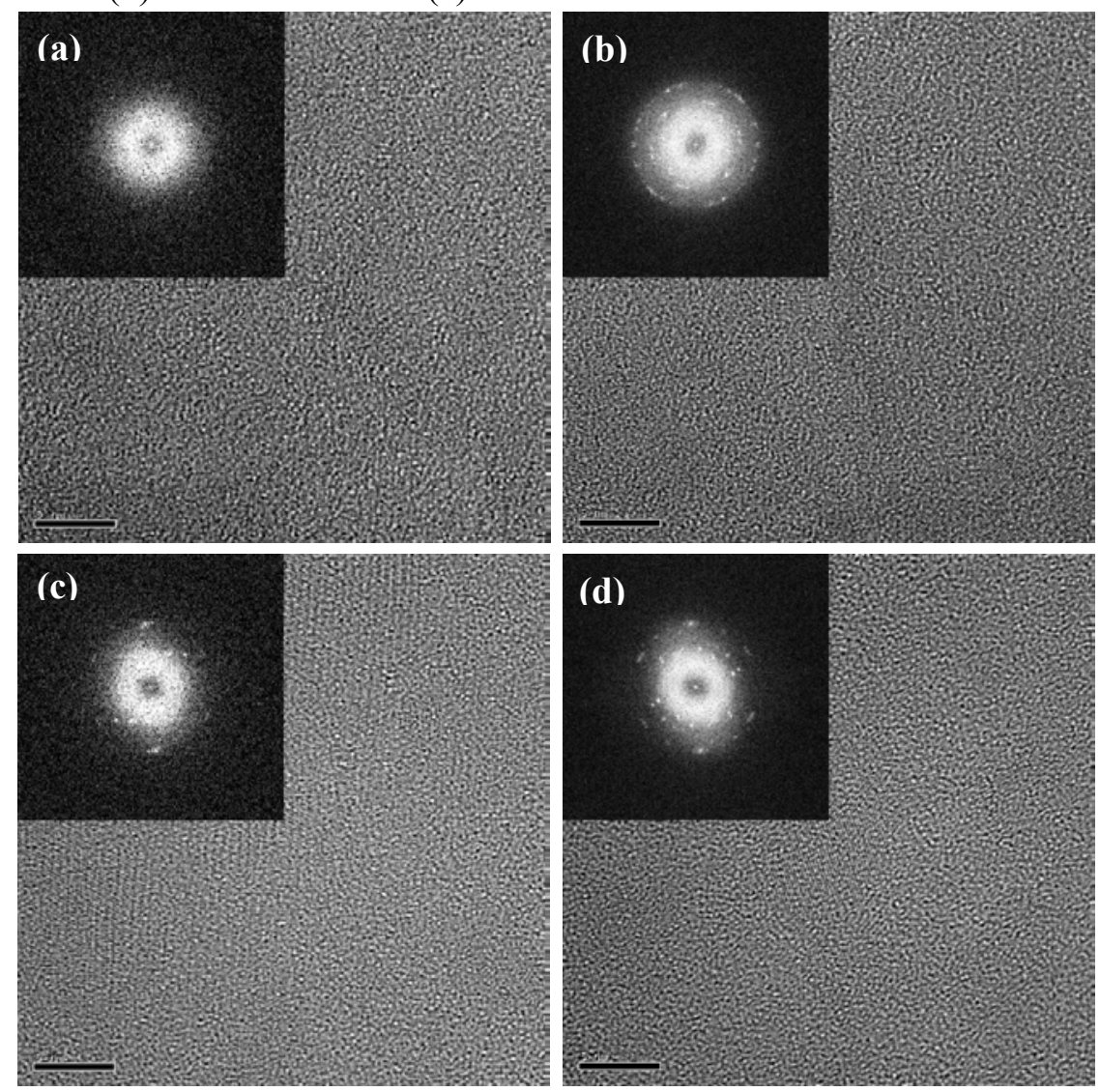

Fig. 2. HVEM images of the $900^{\circ} \mathrm{C}$-heated kaolinite after (a) $3 \mathrm{~min}$ and (b) $30 \mathrm{~min}$ electron irradiation. Mullite crystals of randomly oriented are formed without the spinel-type phase.HVEM images of the $940^{\circ} \mathrm{C}$-heated kaolinite after (c) $8 \mathrm{~min}$ and (d) 30min electron irradiation. The spineltype pahse which is produced in advance of the mullite phase persists with the mullite phase. Insets are the FFT results of each HVEM image. 